\title{
Ocorrência de pinta preta, causada por Guignardia citricarpa, em tangerineiras 'Montenegrina' no sul do Paraná
}

\author{
William Mário Carvalho Nunes, José Croce Filho, José Junior Severino, Carlos Alexandre Zanutto, Dauri José \\ Tessmann, Rudimar Maficioli, Maria Júlia Corazza-Nunes \& João Batista Vida.
}

Núcleo de Pesquisa em Biotecnologia Aplicada, Universidade Estadual de Maringá, Av. Colombo, 5790. CEP 87020-900, Maringá, PR, e-mail: wmcnunes@uem.br

Data de chegada: 08/11/2004. Aceito para publicação em: 16/08/2005.

A mancha preta ou pinta preta dos citros, causada por Guignardia citricarpa Kiely [Phyllosticta citricarpa (McAlp.) van der Aa.], foi registrada no Brasil pela primeira vez em 1980, no Rio de Janeiro, afetando pomares comerciais de mexerica do 'Rio', nos municípios de São Gonçalo e Itaboraí, na baixada fluminense. Em São Paulo a doença foi constatada nos municípios de Conchal e Engenheiro Coelho, em 1992, afetando limoeiros e laranjeiras doces. No Rio Grande do Sul a doença foi constatada em 1986 afetando tangerineiras 'Montenegrina', no vale do Rio Caí.

Em amostras de tangerinas 'Montenegrina' (Citrus deliciosa Tenore), oriundas da região produtora no sul do Estado do Paraná, no município de Cerro Azul, constatou-se a presença da doença pinta preta pelos sintomas apresentados. Há vários tipos de lesões, nomeados de acordo com suas características, que podem variar dependendo do tamanho do fruto, condição climática e tipo de esporo responsável pela infecção. No Brasil foram relatados seis diferentes tipos de sintomas e o que observou-se nas amostras analisadas foi a lesão com o centro necrótico deprimido, marrom claro, com as bordas salientes, apresentando pontos escuros, os picnídios, no interior da lesão. A partir dessas amostras foi realizado o isolamento do patógeno em meio de cultura à base de cenoura. Para confirmação da identidade do fungo, realizou-se análise molecular com uso de iniciadores específicos para G. citricarpa (iniciador op08 e op09) e G. mangiferae (iniciador GCF2 e GCR4) (Figura 1).
Essa é a primeira constatação dessa doença no Estado do Paraná, salientando-se que a região onde foi encontrada a doença localiza-se a mais de $500 \mathrm{~km}$ da região Noroeste, onde se encontra a maior área produtora de laranja doce (Citrus sinensis Osbeck) do Estado.

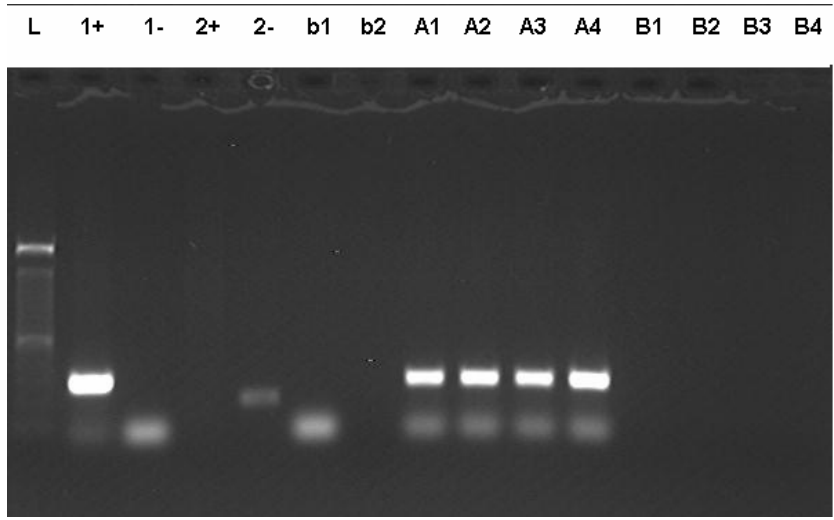

Figura 1. Gel de agarose com o resultado da reação de PCR onde $\mathrm{L}=$ marcador molecular $100 \mathrm{pb} ; 1+=$ controle positivo (primer op08 e op09); $1-=$ controle negativo (primer op08 e op09); $2+=$ controle positivo (primer GCF2 e GCR4); 2-= controle negativo (primer GCF2 e GCR4); b1 e b2= brancos; A1, A2, A3 e A4 = amostras (primer op08 e op09); B1, B2, B3 e B4 = amostras (primer GCF2 e GCR4). 